\title{
Application of SVC on IEEE 6 Bus System for Optimization of Voltage Stability
}

\author{
Sita Singh ${ }^{{ }^{1}}$, Jitendra Hanumant ${ }^{2}$, Ashutosh Kashiv ${ }^{3}$ \\ Electrical \& Electronics Engineering Department, Oriental University \\ Opposite Revati Range Gate no. 1, Sanwer Road, Jakhya, Indore, MP, India 453555 \\ e-mail: sitasigh200711@gmail.com ${ }^{1}$, jitendrahanumant9@gmail.com² ${ }^{2}$, ashutosh.kashiv@gmail.com ${ }^{3}$
}

\begin{abstract}
The problem of voltage or current unbalance is gaining more attention recently with the increasing awareness on power quality. Excessive unbalance among the phase voltages or currents of a three phase power system has always been a concern to expert power engineers. The study of shunt connected FACTS devices is an associated field with the problem of reactive power compensation related problems in today's world. In this study an IEEE-6 bus system has been studied \& utilized in order to study the shunt operation of FACTS controller to optimize the voltage stability
\end{abstract}

Keywords: voltage stability, voltage collapse, Newton Raphson for load flow, SVC, IEEE - 6 bus system

\section{Introduction}

At the present time, power systems are forced to operate at almost full capacity. More and more often, generation patterns result in heavy flows that tend to incur greater losses as well as threatening stability and security of the system. This ultimately creates undesirably increased risk of power outages of different levels of severity [1]. A traditional alternative to reinforce the power network consists of upgrading the electrical transmission system infrastructure through the addition of new transmission lines, substations, and associated equipment. However, the processes to allow, locate, and create new transmission line has become tricky, costly, time taking and numerous times even controversial [7].

On the other hand, FACTS device, which can provide direct and flexible control of power transfer and are very helpful in the operation of power network. When it is been discussed about the power system performance and the power system stability we can enhance by using FACTS device [8-9]. Static VAR compensator (SVC) is one of the most effective measure device for enhancing the power stability and power transfer capability of transmission network, in this SVC it should be properly installed in the system with uniform parameter setting. The some factors considering for optimal installation and the optimal parameter of SVC, in which we improve Stability margin, power loss decline, power collapse avoidance and power transmission capability enhancement $[15,12,20]$. This study deals with the objective to optimize power system voltage stability .This is achieved through IEEE- 6 Bus system, using Newton Raphson load flow analysis and then by placing the SVC on the weakest bus to attain the maximum possible voltage stability.

\section{Voltage Stability \& Collapse}

A power system is claimed to be voltage stable if it is ready to maintain voltages similar to the steady values once subjected to small disturbances. At any instant of your time, the ability system operative condition should be in stable limits, summit completely different operational criteria; furthermore it ought to even be secure within the event of any credible incident [1]. Voltage instability issues disturbances during installation of network wherever the voltage magnitude becomes uncontrollable and eventually ensuing into a collapse of voltage magnitude. The voltage decline is usually monotonous within the starting of the collapse and sophisticated to note. Voltage decline increase typically marks the top of the collapse. Itl's troublesome to differentiate this development from transient stability whereas voltages can also decrease in a manner just like voltage collapse $[2,17]$. Post-disturbance analysis could solely be in those cases reveal the actual cause throughout the last twenty years there are one or 
many giant voltage collapses virtually per annum somewhere round the world. The explanation behind it is terribly clear, those is that the accumulated variety of interconnections and a better degree of utilization of the ability system and alter in load characteristics. Nearly every type of contingencies and even slow-developing load will increase might cause a voltage stability drawback [11]. The duration for the course of events that change into a collapse varies from seconds to many tens of minutes. This makes voltage collapse troublesome to investigate since there are several other phenomena that act together around this point. Necessary factors that cause interaction throughout a voltage decline are: generation limitation, behaviour of on-load tap changers, and load characteristic. A motivating purpose is that several researchers discard voltage magnitude as an appropriate indicator for the proximity to voltage collapse, though this is often indeed the amount that collapses. One question that has been mentioned is whether or not voltage stability could be a static or dynamic method. These days it is widely accepted as a dynamic development however abundant analysis is performed victimises static models [3-5].

\section{Proposed Work}

SVC is one of the most effective devices for enhancing the voltage magnitude stability known. An IEEE-6 bus system is studied using the load flow equations through MATLAB programming. Load flow solutions are being carried out through Newton-Raphson Method. First this is done without the SVC for the load change on the weakest bus known and then the collapse point for the same is been figured out. Then with the collapse point reactive power at load side is increased by $5 \%, 10 \%$ and so on in steps of $5 \%$ upto $30 \%$ and have performed power flow analysis for each, a report for the same has been stored for comparative analysis. The results of the original system \& the system with SVC implemented are hence found out to be almost same and hence the system is voltage stable with SVC even on maximum load on the weakest bus. Power flow analysis is been performed using Newton Raphson Algorithm which is explained as in next section.

\section{Algorithm Used}

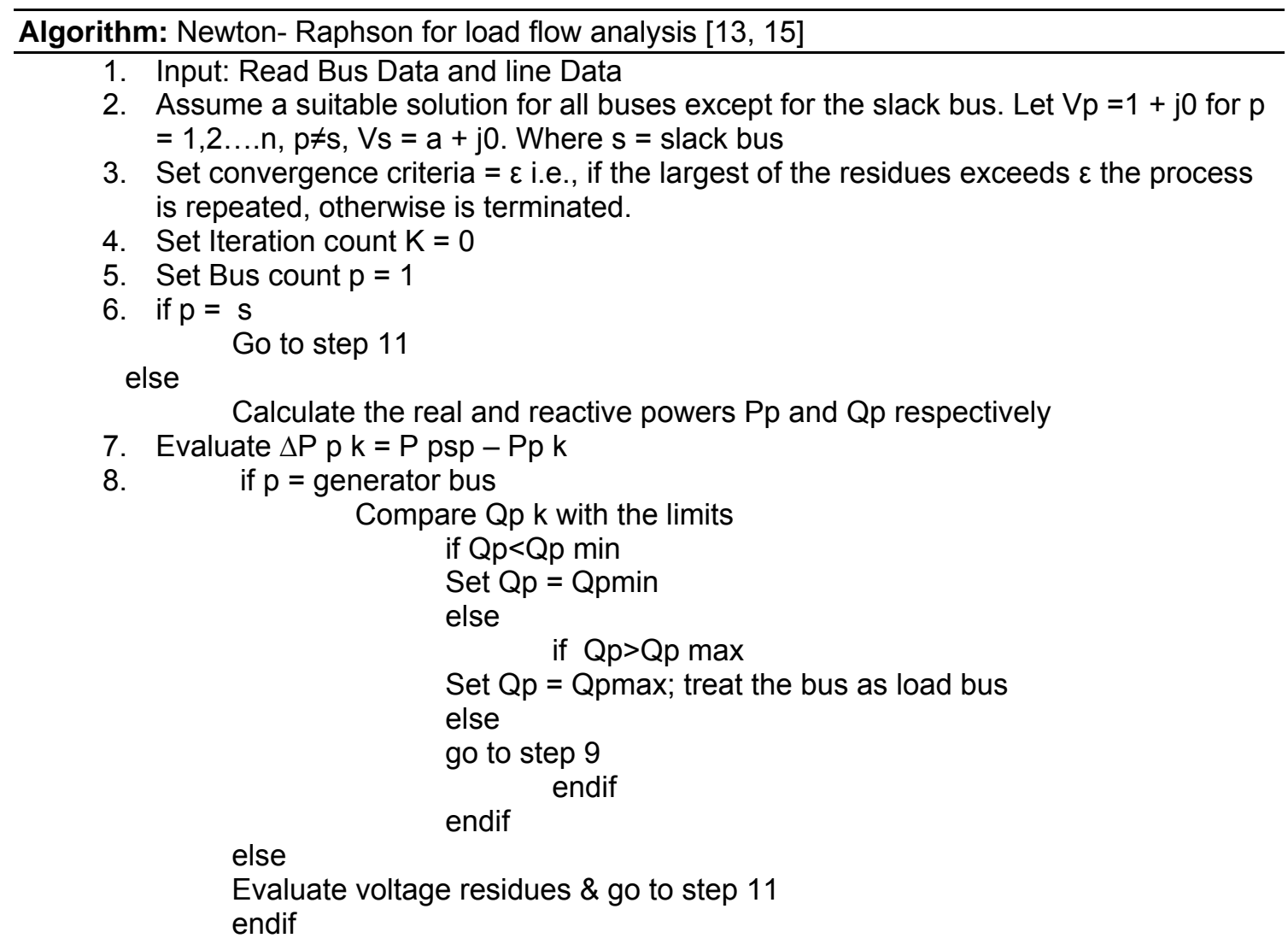

IJEEI Vol. 3, No. 1, March 2015: 1-6 
8. Evaluate $\Delta Q p k=Q p s-Q p k$

9. Set $p=p+1$

endif

10. if $p>n$

Determine the largest of the absolute value of residue

else

endif

Go to step 6

11. if residue $\leq \varepsilon$

Go to step 15

else

endif

Evaluate elements for Jacobian matrix

12. Calculate voltage increments $\Delta \mathrm{epk}$ and $\Delta \mathrm{f} p \mathrm{pk}$

13. Evaluate $\cos \delta$ and $\sin \delta$ of all voltages.

14. if $p=$ generator bus?

Calculate e $\mathrm{pk}+1$ and $\mathrm{p} \mathrm{k+1}$ for generator bus

else

if $|V p|<|V p \min |$

Calculate e $\mathrm{pk}+1$ and $\mathrm{p} \mathrm{k+1}$ for minimum condition.

else

if $|V p|>|V p \max |$

Calculate e $\mathrm{pk}+1$ and $\mathrm{p} \mathrm{k}+1$ for maximum condition.

else

Advance iteration count $\mathrm{K}=\mathrm{K}+1$ and go to step 5

15. Evaluate bus and line powers and print the results.

\section{Results and Discussions}

IEEE- 6 bus consists of 3 synchronous generators with IEEE type- 1 exciters, 2 of which are synchronous compensators used only for reactive power support. There are total load of 40 MW and 18 Mvar distributed in 4 load buses. Bus 1 is slack bus which is denoted by Type 1; Bus 2 is Generating Bus which is denoted by Type 2; Bus 3, Bus 4, Bus $5 \&$ Bus 6 are the load busses which are denoted by Type 0 .

Load flow results for IEEE6 bus system shows that the weakest bus on the system is Bus - 3. It is required now to determine the point of collapse where the application of SVC can be implemented to improve and check for voltage stability. Load flow analysis for the system is performed with changing load. It was found at Bus -3 that the voltage magnitude is drooping in characteristic as can be seen from the Table 1. Figure 1 show the drooping plot of PV curve for load increased to $120 \mathrm{MW}$.

On further increasing the load, the drop in the magnitude of voltage is being steeper. At the load of $129 \mathrm{MW}$, the load flow solution did not converge; still giving a solution in the range of voltage drop \& not in the range of voltage collapse. Also it means that on Bus 3 maximum loadability is around $129 \mathrm{MW}$. When load is increased to $129 \mathrm{MW}$, voltage magnitude of Bus 3 was $0.625 \mathrm{pu}$ and when the load is $129.500 \mathrm{MW}$, voltage magnitude of Bus 3 reaches to -0.743 $\mathrm{pu}$. The plot of the PV curve is shown in Figure 2.

After the load of $129.5 \mathrm{MW}$, Bus 3 become voltage magnitude becomes negative so it will be the point of collapse at this condition. Compensation can be applied on the maximum load (or collapse point) to achieve voltage stability. 
Table 1. The voltage magnitude at Bus -3

\begin{tabular}{ccc}
\multicolumn{2}{c}{ LOAD } & \\
Pg (MW) & $\begin{array}{c}\text { Qg } \\
\text { (Mvar) }\end{array}$ & \\
\hline 10 & 6.5 & $\mathbf{0 . 9 5 6}$ \\
15 & 6.5 & $\mathbf{0 . 9 5 3}$ \\
20 & 6.5 & $\mathbf{0 . 9 4 9}$ \\
25 & 6.5 & $\mathbf{0 . 9 4 6}$ \\
30 & 6.5 & $\mathbf{0 . 9 4 1}$ \\
35 & 6.5 & $\mathbf{0 . 9 3 7}$ \\
40 & 6.5 & $\mathbf{0 . 9 3 2}$ \\
45 & 6.5 & $\mathbf{0 . 9 2 7}$ \\
50 & 6.5 & $\mathbf{0 . 9 2 1}$ \\
55 & 6.5 & $\mathbf{0 . 9 1 5}$ \\
60 & 6.5 & $\mathbf{0 . 9 0 9}$ \\
65 & 6.5 & $\mathbf{0 . 9 0 2}$ \\
70 & 6.5 & $\mathbf{0 . 8 9 4}$ \\
75 & 6.5 & $\mathbf{0 . 8 8 5}$ \\
80 & 6.5 & $\mathbf{0 . 8 7 6}$ \\
85 & 6.5 & $\mathbf{0 . 8 6 6}$ \\
90 & 6.5 & $\mathbf{0 . 8 5 5}$ \\
95 & 6.5 & $\mathbf{0 . 8 4 3}$ \\
100 & 6.5 & $\mathbf{0 . 8 2 9}$ \\
105 & 6.5 & $\mathbf{0 . 8 1 4}$ \\
110 & 6.5 & $\mathbf{0 . 7 9 6}$ \\
115 & 6.5 & $\mathbf{0 . 7 7 5}$ \\
120 & 6.5 & $\mathbf{0 . 7 4 8}$ \\
\hline & & \\
& &
\end{tabular}

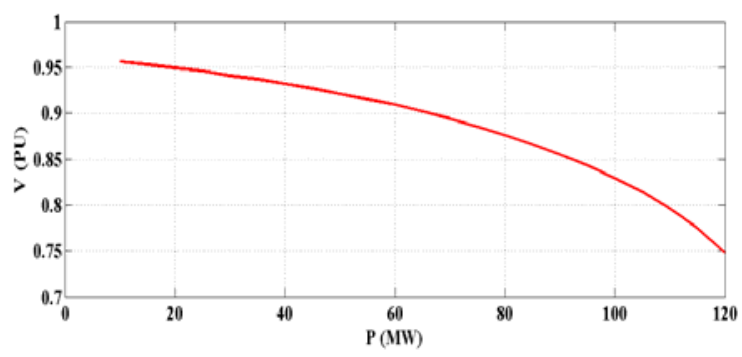

Figure 1. The drooping plot of PV curve for load increased to $120 \mathrm{MW}$

Table 2. The voltage magnitude of maximum loadability

\begin{tabular}{ccc}
\multicolumn{2}{c}{ LOAD } & Voltage Mag. \\
\cline { 1 - 2 } Pg (MW) & $\begin{array}{c}\text { Qg } \\
\text { (Mvar) }\end{array}$ & \\
\hline 125 & 6.5 & $\mathbf{0 . 7 0 9}$ \\
126 & 6.5 & $\mathbf{0 . 6 9 8}$ \\
127 & 6.5 & $\mathbf{0 . 6 8 5}$ \\
128 & 6.5 & $\mathbf{0 . 6 6 6}$ \\
128.5 & 6.5 & $\mathbf{0 . 6 4 9}$ \\
129 & 6.5 & $\mathbf{0 . 6 2 5}$ \\
129.5 & 6.5 & $\mathbf{- 0 . 7 4 3}$ \\
\hline
\end{tabular}

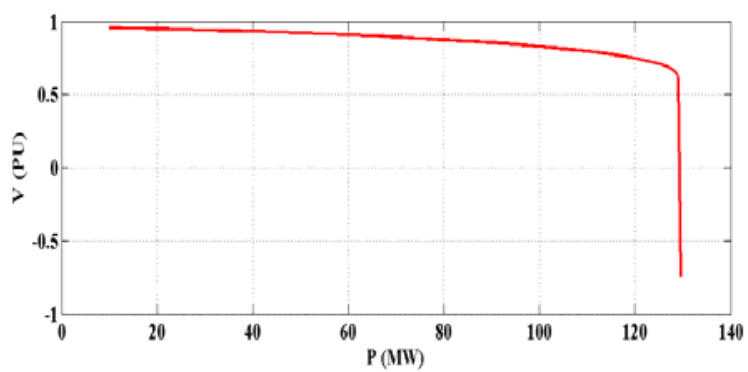

Figure 2. The plot of the PV curve when the load is $129.500 \mathrm{MW}$ 


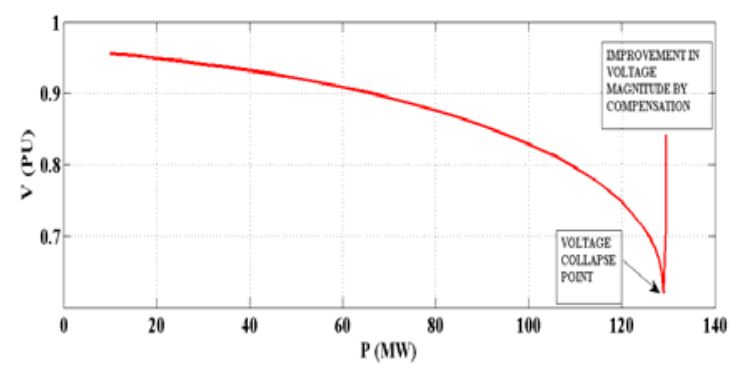

Figure 3. The plot of the PV curve with SVC compensating $25 \mathrm{Mvar}$

As seen from the plot in Figure 3 at the very same point of voltage collapse; at a load of 129.5 MW; compensating with SVC with $25 \mathrm{Mvar}$; voltage magnitude has again reached in the stable region. Also it is known that applying compensation above $30 \%$ becomes costlier than implementing a new system; hence this is the maximum stability that can be achieved through implementing SVC on IEEE 6 Bus System on maximum load to avoid voltage collapse.

Table 3

\begin{tabular}{cccc}
\hline \multicolumn{2}{c}{ LOAD } & $\begin{array}{c}\text { Voltage } \\
\text { Mag. }\end{array}$ & $\begin{array}{c}\text { Injected } \\
\text { Mvar }\end{array}$ \\
\hline Pg (MW) & (Mvar) & & \\
\hline 129.5 & 6.5 & $\mathbf{0 . 7 1 4}$ & 5 \\
129.5 & 6.5 & $\mathbf{0 . 7 5 7}$ & 10 \\
129.5 & 6.5 & $\mathbf{0 . 7 9}$ & 15 \\
9.5 & 6.5 & $\mathbf{0 . 8 1 8}$ & 20 \\
129.5 & 6.5 & $\mathbf{0 . 8 4 3}$ & 25 \\
\hline
\end{tabular}

From the study it can be concluded the point of maximum loading to be $129.5 \mathrm{MW}$ of load on the weakest bus; Bus 3 and also the optimum voltage stability through implementation of SVC is obtained; that is with application of SVC with reactive injection of Mvar of $25 \mathrm{MW}$ the magnitude of voltage reaches to $0.843 \mathrm{PU}$ from $-0.743 \mathrm{PU}$.

\section{Conclusion \& Future Scope}

From the study it can be concluded the point of maximum loading to be $129.5 \mathrm{MW}$ of load on the weakest bus; Bus 3 and also the optimum voltage stability through implementation of SVC is obtained; that is with application of SVC with reactive injection of Mvar of $25 \mathrm{MW}$. The magnitude of voltage reaches to $0.843 \mathrm{PU}$ from $-0.743 \mathrm{PU}$.

The study has evaluated the maximum load before voltage collapse on a IEEE 6 bus system, the same work can be performed with different standard as well as practical systems to verify and implement it to the existing networks.SVC on its standard rating is been applied here to observe voltage stability, Parameter of SVC can be altered to improve for more voltage stability condition. This study is applied only to AC test System; it can be very well implied on HVDC system and can be verified for the same. SVC is been applied to the test system, there are various other FACTS devices available for stability analysis, like STATCOM, UPFC, SSSC, TCSC etc which individually have different characteristics. Other than FACTS devices, there are various other electronic devices which can be implemented in the same system like OLTC, Tapchanging transformers. Artificial Intelligence \& Fuzzy Logic has emerged as techniques which can be implemented to many realistic power system networks in its various domains. There are various methodologies available which can used to extend this work, through which the weakest bus for any larger system can be evaluated very fastly and accurately. 


\section{References}

[1] Brit KA, Graff JJ, McDonald JD, El-Abiad AH, Three phase load flow program. IEEE Transactions on Power Application System. 1976; 95(1): 59-65.

[2] Mamdouh Abdul Akher, Khalid Mohamed Nora, Abdul Halim Abdul Rachid. Improved three phase power flow methods using sequence components. IEEE Transactions on Power systems. 2005; 20(3): 1389-1397.

[3] Yamile E-Del Valle. Optimization of power system performance using FACTS Devices. IEEE transactions on Power Systems. 2009; 62(2).

[4] Jing Zhang, JY Wen, SJ Cheng, Jia Ma. A Novel SVC allocation method for power system voltage stability enhancement by normal forms of diffeomorphism. IEEE transactions on Power Systems. 2007; 22(4): 1818-1825.

[5] Massoud Amin. Modernizing The National Electric Power Grid. Workshop on Modernizing the National Electric Power Grid EPRI/NSF/ Entergy and DOE. New Orleans, LA. 2002; 18-19.

[6] Chen-Ching Liu, James Momoh and Paul Werbos, Massoud Amin, Aty Edris, and Acher Mosse. NSF/EPRI Workshop on Urgent Opportunities for Transactions on mission System Enhancement, EPRI. Palo Alto, CA. 2012; 11-12.

[7] Clark W Gellings. Power Delivery System of the Future. IEEE Power Engineering Review. 2002; 22(12): 7-12.

[8] Gregory J Miranda. Options for the Cement Industry in the Deregulated Power Era. Cement Industry Technical Conference, In Proceedings of 44th IEEE-IAS/PCA. 2002; 19-28.

[9] C Mensah-bonsu, S Oren. California Electricity Market Crisis: Causes, Remedies, and Prevention. IEEE Power Engineering Review. 2002; 22(8) 4-23.

[10] Brian Cory, Peter Lewis. The Reorganization of the Electric Supply Industry - A critical Review. Power Engineering Journal. 1997; 42: 42-46.

[11] Massoud Amin. Evolving Energy Enterprise-"Grand Challenges": Possible road ahead and challenges for R\&D. IEEE Power Engineering Society Summer Meeting. 2002; 1705-1707.

[12] Narain G Hingorani, Laszlo Gyugyi. Understanding FACTS. IEEE Press. New York: 2000: ISBN 07803-3455-8.

[13] Kundur P. Power System Stability and Control. 1st Edtion. NewYork: Tata McGraw-Hill Education. 1994: ISBN-10: 0070635153

[14] Ajjarapu V. Computational Techniques for Voltage Stability Assessment and Control. $1^{\text {st }}$ Edition. Springer, New York: 2006: ISBN-10: 0387260803.

[15] Mathur RM, RK Varma. Thyristor-Based Facts Controllers for Electrical Transmission Systems. 1st Edition. New York: IEEE Press. 2002: ISBN- 10: 0-4712-0643-1.

[16] Sode-Yome, AN Mithulananthan, KY Lee. Static voltage stability margin enhancement using STATCOM, TCSC and SSSC. Proceedings of IEEE/PES Transmission and Distribution Conference and Exhibition: Asia and Pacific, IEEE Xplore Press Dalian. 2005; 1-6.

[17] Natesan R, G Radman. Effects of STATCOM, SSSC and UPFC on voltage stability. Proc. 36th Southeastern Symposium on System Theory, IEEE Xplore Press. 2004; 546-550.

[18] Gotham DJ, GT Heydt. Power Flow control and Power Flow Studies for Systems with FACTS devices. IEEE Transactions on. Power System. 1998; 13(4): 60-65.

[19] Acha E. Facts: Modelling and Simulation in Power Networks. 1st Edition. Chichester: John Wiley and Sons. 2004: ISBN-10: 0470852712.

[20] Hammad, B Roesle. New Roles for Static VAR Compensators in Transmission Systems. Brown Boveri Review. 1986; 73: 314-320.

IJEEI Vol. 3, No. 1, March 2015: $1-6$ 